\title{
Non-Enzymatic Glucose Sensor Based on the Novel Flower Like Morphology of Nickel Oxide
}

\author{
Z. H. Ibupoto ${ }^{1}$, K. Khun ${ }^{1}$, V. Beni ${ }^{2}$, M. Willander ${ }^{1}$ \\ ${ }^{1}$ Division of Physical Electronics and Nanotechnology, Department of Science and Technology, Linköping University, Campus \\ Norrköping, Norrköping, Sweden; ${ }^{2}$ Department of Physics, Chemistry, and Biology (IFM), Linköping University, Linköping, Swe- \\ den. \\ Email: sukantakutripathy@yahoo.co.in
}

Received October $1^{\text {st }}, 2013$; revised November $13^{\text {th }}, 2013$; accepted November $20^{\text {th }}, 2013$

Copyright (C) 2013 Z. H. Ibupoto et al. This is an open access article distributed under the Creative Commons Attribution License, which permits unrestricted use, distribution, and reproduction in any medium, provided the original work is properly cited.

\begin{abstract}
In this study, novel nickel oxide (NiO) flowers like nanostructures were fabricated onto gold coated glass substrate by hydrothermal method using high alkaline $\mathrm{pH}$ medium. The structural study of nickel oxide nanostructures was performed by scanning electron microscopy (SEM) and X-ray differaction (XRD) techniques. Nickel oxide nanostructures are highly dense, uniform and possess good crystalline quality. The so prepared structures were investigated for their electrochemical properties by cyclic voltammetry and amperometric techniques. The nickel oxide flower like morphology has shown good electrochemical performances for the oxidation of glucose. The presented sensing material was able to detected glucose in a wide range of concentration of $0.001 \mathrm{mM}$ to $8 \mathrm{mM}$ with a high sensitivity $(123 \mu \mathrm{mA} / \mathrm{mM})$ and regression coefficient of 0.99 . Moreover, the $\mathrm{NiO}$ nanostructures based sensor is highly reproducible, stable, exhibiting a fast response time and selective in the response. All the obtained results indicate the potential use of this material in the development of enzyme free sensors for the detection of glucose.
\end{abstract}

Keywords: Nickel Oxide; Non-Enzymatic Sensor; Glucose; Selective; Stable

\section{Introduction}

Due to increase in the number of diabetes patients, the accurate and sensitive detection of glucose has drawn the attention of researchers towards the simple and cheap fabrication of glucose sensors [1]. Updike and Hicks for the first time developed glucose oxidase immobilized amperometric glucose sensor [2]. Afterwards electrochemical biosensors, using glucose oxidase as biorecognition material, have been largely studied and examined [3-5]. Although the glucose sensors using glucose oxidase have several merits such as high sensitivity and selectivity, however the catalytic activity of glucose oxidase is easily reduced by variations in $\mathrm{pH}$, temperature, humidity and by the interference offered by other substances. Recently, non-enzymatic glucose sensors are becoming more popular due to their acceptable reproducibility, stability, low costs and simplicity. Several metal oxides nanostructures based non-enzymatic glucose sensors have been reported such as $\mathrm{NiO}$ [6-8], $\mathrm{MnO}_{2}$ [9], $\mathrm{Co}_{3} \mathrm{O}_{4}$ [10], $\mathrm{CuO}$ [11]. Still more work is required in the fabrication of non-enzymatic glucose sen- sors for improving their sensitivity and selectivity.

The nickel oxide (NiO) nanomaterial with homogenous size and well defined dispersion is highly demanded for the various applications such as designing ceramic, magnetic, electrochromic and heterogeneous catalytic materials [12]. Different synthetic routes have been proposed for the fabrication of $\mathrm{NiO}$ nanomaterial including sol-gel [13], surfactant mediated synthesis [14], thermal decomposition [15] and polymer matrix assisted preparation [16]. Some of the above mentioned growth routes are facing problems in the uniform size and well dispersion of $\mathrm{NiO}$ nanoparticles.

The hydrothermal method for the growth of various nanomaterials is also known as super-heated hydrothermal solution based method. Hydrothermal method is considered environmentally benign and it can be used for the growth of various nanomaterials even in strong solvents in the closed system. Moreover, hydrothermal method is inexpensive, simple and yields high purity of desired product, thus it is a highly suitable method from industrial point of view. To date, several methods have 
been proposed for the synthesis of $\mathrm{NiO}$ nanoparticles and nanorods, but few reports have been published for the preparation of porous nanosheets $[17,18]$. Nickel oxide is the material which can easily be grown by hydrothermal method with high yield on the substrate.

In this work, novel $\mathrm{NiO}$ nanoflowers have been synthesized by the hydrothermal method and successfully applied for the development of enzyme free glucose sensor by cyclic voltammetry and amperometric measurements. The sensor electrode is very stable, reproducible, repeatable, sensitive and selective.

\section{Experimental Section}

\subsection{Used Materials}

Nickel nitrate hexahydrate, hexamethylenetetramine, 25\% ammonia, nitric acid d-glucose, ascorbic acid, uric acid and dopamine were purchased from Sigma Aldrich Sweden. All other chemical used were of analytical standard.

\subsection{The Synthesis of NiO Nanostructures on the Gold Coated Glass Substrate}

The coating of gold layer on the glass substrate was done according to our previous work [19]. The synthesis of $\mathrm{NiO}$ was carried out in two steps. Firstly nickel hydroxide $\mathrm{Ni}(\mathrm{OH})_{2}$ was grown the gold coated glass substrate by hydrothermal growth approach using the equimolar $0.1 \mathrm{M}$ solution of nickel hexahydrate and hexamethylenetetramine. Nickel hydroxide was grown in alkaline medium of $\mathrm{pH} 11$ and the $\mathrm{pH}$ of growth solution was adjusted by using few drops f $25 \%$ ammonia and $0.1 \mathrm{M}$ nitric acid. The gold electrodes were cleaned in the isopropanol in the ultrasonic bath for 10 - 15 minutes, then were washed with the deionized water and dried with the nitrogen gas at room temperature. Afterwards, the gold electrodes were affixed in the Teflon sample holder and vertically dipped in the growth solution and left in the preheated oven at $98^{\circ} \mathrm{C}$ for 4 - 6 hours. Secondly, after the synthesis of nickel hydroxide the conversion of nickel hydroxide into $\mathrm{NiO}$ was performed by annealing the nickel hydroxide grown samples at $450^{\circ} \mathrm{C}$ for $2-3$ hours.

Scanning electron microscopy and X-ray differaction techniques were used for the morphological and crystal studies of prepared $\mathrm{NiO}$ nanostructures respectively. The prepared $\mathrm{NiO}$ nanostructures were used for the development of enzyme free glucose sensor and the electrochemical measurements were performed by the potentiostat/galvanostat FRA $2 \mu$ Autolab type (III) model. The electrochemical cell used in the proposed work was a three electrode system, $\mathrm{NiO}$ nanostructures were used as the working electrode, platinum wire as counter electrode and silver-silver chloride wire as reference electrode. The glucose solution was prepared in the deionized water and all measurements were carried out in $0.1 \mathrm{M} \mathrm{NaOH}$ solution with successive addition of glucose solution.

\section{Results and Discussions}

\subsection{The Structural Study of as Grown NiO Nanostructures on the Gold Coated Glass Substrate}

The morphology of as prepared $\mathrm{NiO}$ nanostructures was investigated by using the scanning electron microscopy and the obtained nanostructures are shown in Figure 1. It can be seen from the Figure 1(a) that $\mathrm{NiO}$ nanostructures are composed of nanoflowers that are synthesized in alkaline $\mathrm{pH}$ medium [11]. The nanostructures resemble a rose flower like morphology with average thickness of 10 - $20 \mathrm{~nm}$. Figure 1(b) shows the high magnification image of nanoflowers and it can be observed that nanostructures are highly dense, uniform and covered the whole substrate area. Energy dispersive X-ray analysis has shown the pure composition of $\mathrm{NiO}$ nanostructures presented in this study as shown in Figure 1(c). For the analysis of crystalline array of $\mathrm{NiO}$ nanostructures, $\mathrm{X}$-ray differaction technique was used and the measured XRD spectrum is shown in Figure 2. The observed crystal planes include (012), (110) and (113) which are the characteristic peaks of $\mathrm{NiO}$ and supported by JCPDS card no: (47-1049). One of the NiO peak is merged with the very intense peak of gold due gold coating on the glass substrate.

\subsection{The Cyclic Voltametric and Amperometric Measurement of the Proposed Enzyme Free Glucose Sensor Using NiO Nanostructures}

The electro catalytic activity of $\mathrm{NiO}$ flower-like nanostructured electrode taword the oxidation of glucose was studied by cyclic voltammetry (CV). Figure 3 shows the $\mathrm{CV}$ response of the bare gold electrode and $\mathrm{NiO}$ grown gold electrode in the different concentrations of glucose in $0.10 \mathrm{M} \mathrm{NaOH}$ solution at the scan rate of $10 \mathrm{mV} / \mathrm{s}$. As it can be seen from this Figure a clear oxidation wave is recorded; this wave is increasing wit the concentration of the glucose. Likewise, the oxidative potential was slightly shifted positively. Figure 4 shows the influence of scan rate, between 10 and $100 \mathrm{mV} / \mathrm{s}$, on the current response. As it can be observed from this Figure 4(a) the oxidative current peak is enhanced with the raise of scan rate; the plot of the current vs the square root of the scan rate showed a linear behaviour indicating that the process is diffusion controlled.

Figure 5 shows the amperometric response of the $\mathrm{NiO}$ nanostructures based sensor electrode measured at +0.5 $\mathrm{V}$ in $0.1 \mathrm{M} \mathrm{NaOH}$ solution. Upon the addition of different concentrations of glucose, it can be found that $\mathrm{NiO}$ 


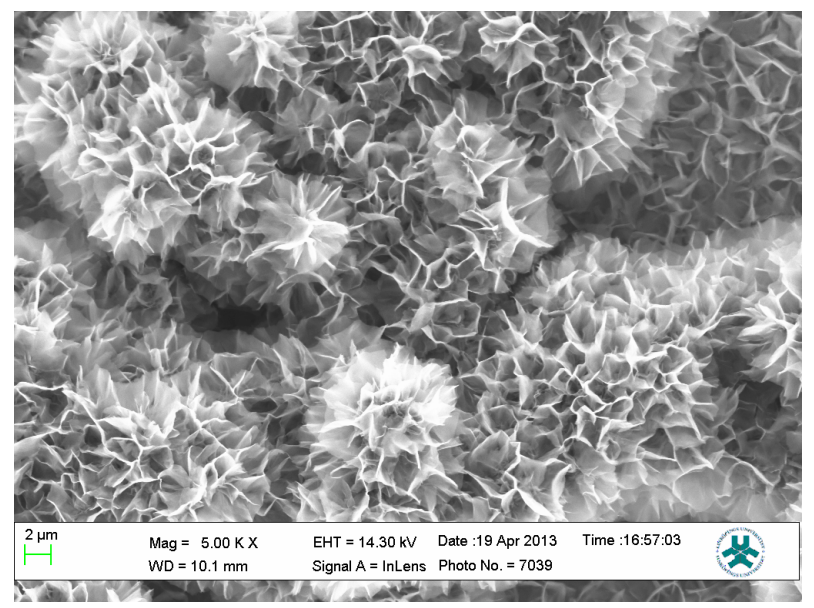

(a)

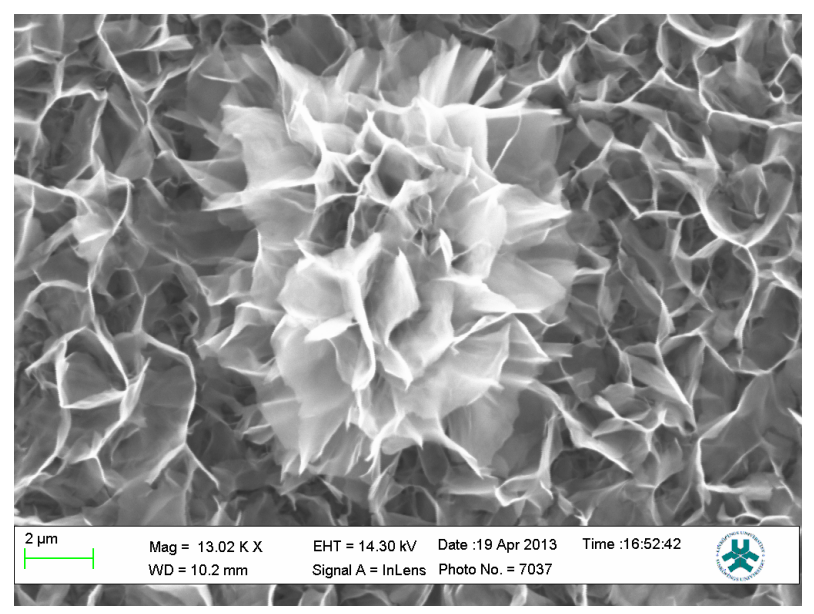

(b)

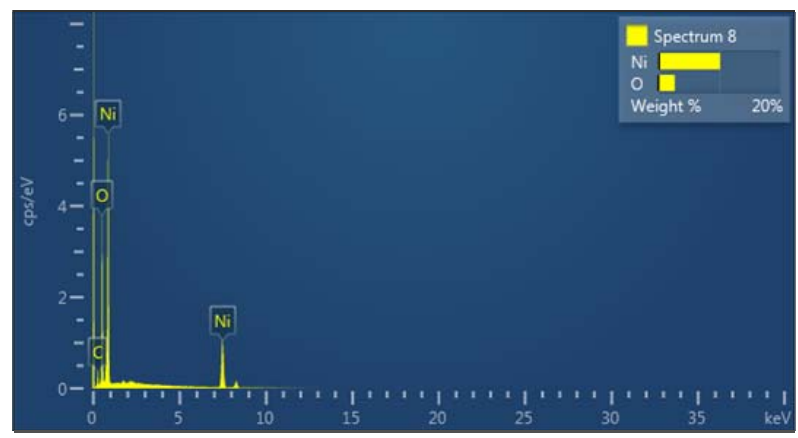

(c)

Figure 1. a) SEM image at low magnification; b) SEM image at high magnification; c) EDX spectrum.

based electrode showed acceptable amperometric response to various concentrations of glucose with the sensitivity of $120 \mu \mathrm{mA} / \mathrm{mM}$ and regression coefficient value of $\mathrm{R}=0.99$. The nickel oxide nanoflowers like morphology have shown a linear response for the range of 10 $\mu \mathrm{M}$ to $10 \mathrm{mM}$ concentration of glucose. The detection limit was found to be $1 \mu \mathrm{M}$ and a fast response time of less than $10 \mathrm{~s}$ was also noticed during the experiments.

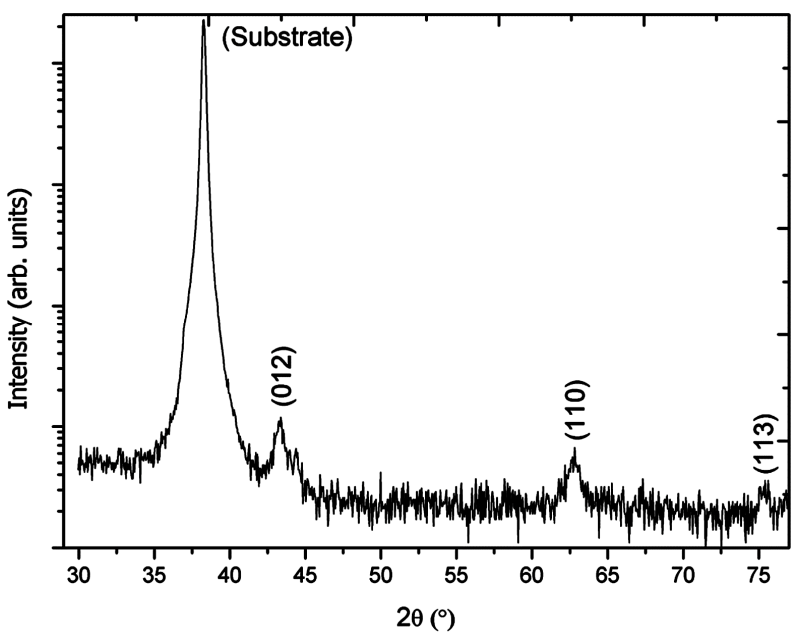

Figure 2. X-ray differaction pattern study of NiO nanoflowers.

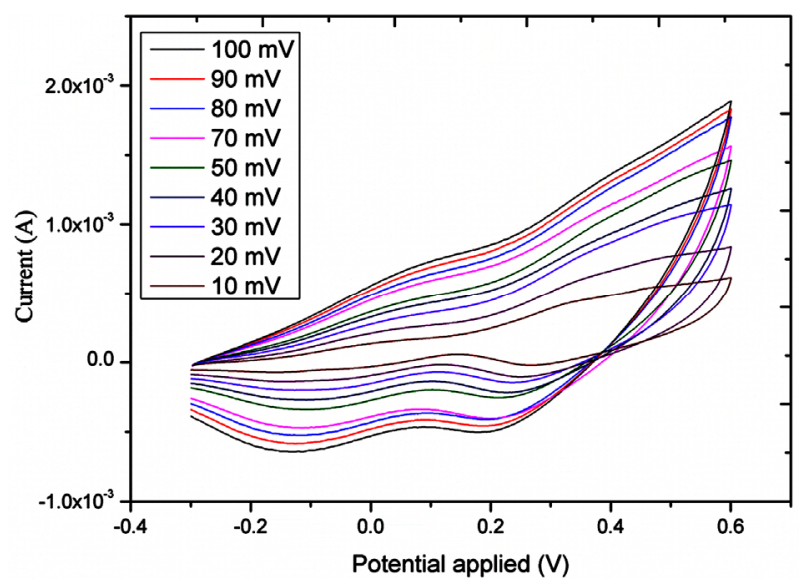

(a)

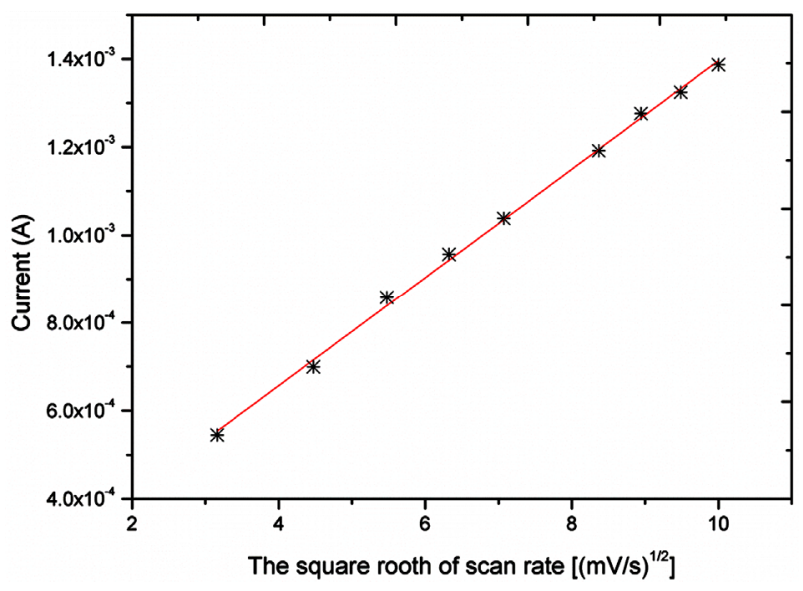

(b)

Figure 3. a) cyclic voltametric response at different scan rates into $1.91 \mathrm{mM}$; b) current Vs square root of scan rate.

The high sensitivity and fast response time of the presented enzyme free glucose sensor can be attributed to high surface to volume ratio of flower like morphology 


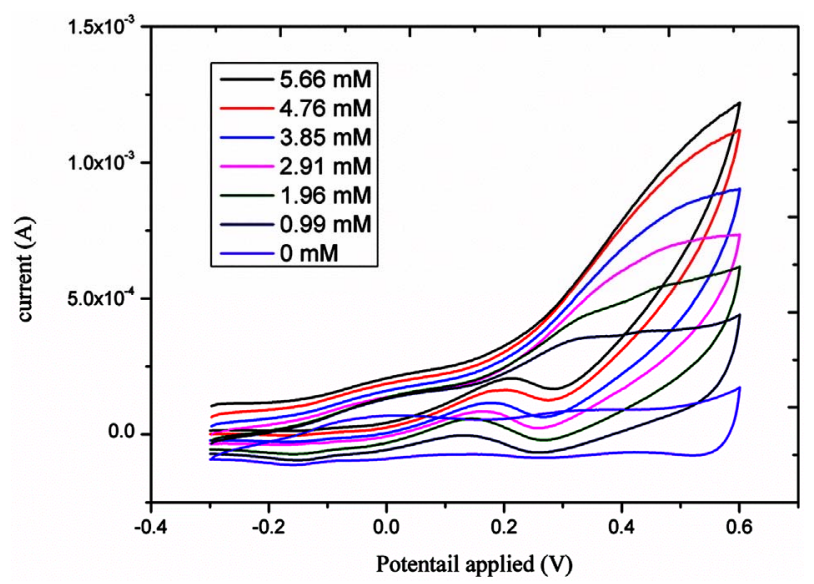

Figure 4. Cyclic voltametric response for the different concentrations of glucose from 0.99 to $5.66 \mathrm{mM}$.

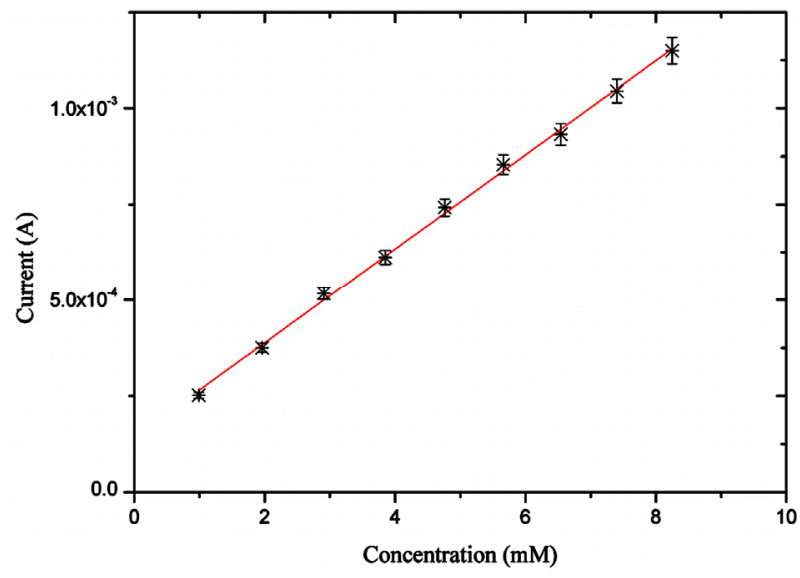

Figure 5. Amperometric response of the proposed enzyme free glucose sensor for the different concentrations of glucose from $1 \mathrm{mM}$ to $8 \mathrm{mM}$.

of $\mathrm{NiO}$ which enhanced the electro catalytic performance of the material.

The selectivity of the particular sensor is related to its response for the specific analyte in the presence of other competing species. Especially for the glucose sensor different interfering biomolecules have been reported including ascorbic acid, dopamine, uric acid and other carbohydrates. All these interferents coexist with glucose in the human serum. The human serum contains glucose concentration 30 times higher than that of ascorbic acid, dopamine, and uric acid. The amperometric response for the selectivity of NiO nanoflowers like morphology sensor electrodes was measured by the addition of $1 \mathrm{mM}$ glucose followed by the addition of $0.05 \mathrm{mM}$ ascorbic acid, dopamine and uric acid respectively as shown in Figure 6. By comparing the current response of glucose with the common interferents, it can be concluded that $\mathrm{NiO}$ nanostructures based glucose sensor is very selective and shown negligible response for other competing

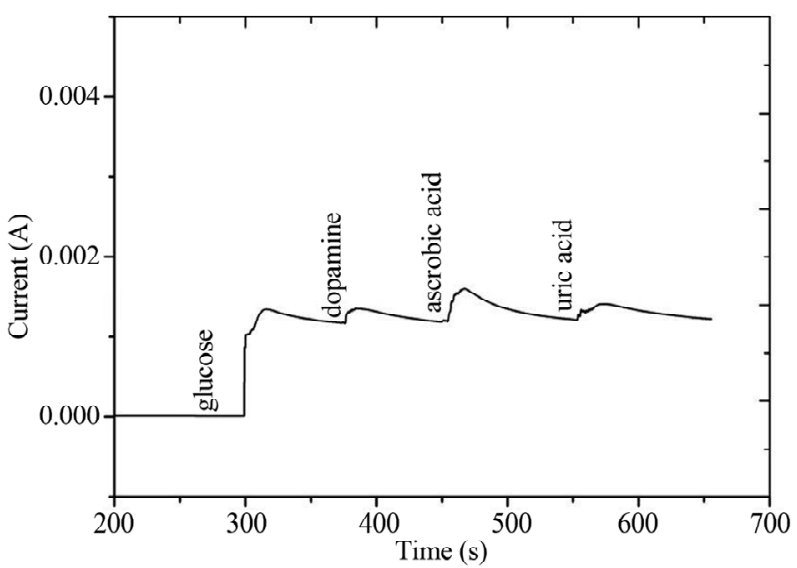

Figure 6. The interference response of the developed glucose sensor in the presence of common interferents for 1 $\mathrm{mM}$ concentration of each of the component.

substances.

The reproducibility and stability were also examined for the developed $\mathrm{NiO}$ nanoflowers based glucose sensor electrode. Five independent $\mathrm{NiO}$ nanostructures based sensor electrodes were prepared under the similar conditions and their current response was measured in $1 \mathrm{mM}$ glucose at the applied potential of $+0.5 \mathrm{~V}$. The relative standard deviation was found to be less than $5 \%$ that confirmed highly reproducible response of the proposed $\mathrm{NiO}$ based glucose sensor. The stability of the sensor electrode was evaluated for more than three weeks and the sensor electrode maintained its original activity of $90 \%$ without undergoing the poisons through the formation of oxidation product. This experiment indicated that sensor electrode can be used for more than one time without any abrupt change in the response of the sensor electrode.

\section{Conclusion}

In the present study, $\mathrm{NiO}$ nanoflowers like morphology are grown on the gold coated glass substrate by hydrothermal method in alkaline $\mathrm{pH}$ medium. The gold electrode is fully covered with the $\mathrm{NiO}$ nanostructures and $\mathrm{NiO}$ nanostructures exhibit good crystalline quality. The so prepared $\mathrm{NiO}$ nanostructures were demonstrated to be suitable for the development of enzyme free glucose sensor. The sensor showed high sensitivity, low limit of detection $(1 \mu \mathrm{M})$, a fast response time $(<10 \mathrm{~s})$ and detected the glucose in wide range of concentrations (10 $10,000 \mu \mathrm{M})$. The fabricated sensor is also associated with good reproducibility and high stability indicating its high potentiality for the development of enzyme free sensors.

\section{REFERENCES}

[1] Z. Yang, J. Feng, J. Qiao, Y. Yan, Q. Yu and K. Sun, "Copper Oxide Nanoleaves Decorated Multi-Walled Car- 
bon Nanotube as Platform for Glucose Sensing," Analytical Methods, Vol. 4, No. 7, 2012, pp. 1924-1926. http://dx.doi.org/10.1039/c2ay25283j

[2] G. P. Hicks and S. J. Updike, “The Enzyme Electrode,” Nature, Vol. 214, 1967, pp. 986-988. http://dx.doi.org/10.1038/214986a0

[3] L. Hu, S. Han, Z. Liu, S. Parveen, Y. Yuan and G. Xu, “A Versatile Strategy for Electrochemical Detection of Hydrogen Peroxide as well as Related Enzymes and Substrates Based on Selective Hydrogen Peroxide-Mediated Boronate Deprotection," Electrochemistry Communication, Vol. 13, No. 12, 2011, pp. 1536-1538. http://dx.doi.org/10.1016/j.elecom.2011.10.016

[4] A. M. Vinu Mohan, K. K. Ashwini, A. Maria Starvin and V. M. Biju, “Amperometric Detection of Glucose Using Prussian Blue-Graphene Oxide Modified Platinum Electrode,” Analytical Methods, Vol. 5, No. 7, 2013, pp. 17641770. http://dx.doi.org/10.1039/c3ay26310j

[5] V. Mani, B. Devadas and S. M. Chen, "Direct Electrochemistry of Glucose Oxidase at Electrochemically Reduced Graphene Oxide-Multiwalled Carbon Nanotubes Hybrid Material Modified Electrode for Glucose Biosensor,” Biosensor Bioelectronic, Vol. 41, 2013, pp. 309-315. http://dx.doi.org/10.1016/j.bios.2012.08.045

[6] A. Sun, J. Zheng and Q. Sheng, "A Highly Sensitive NonEnzymatic Glucose Sensor Based on Nickel and MultiWalled Carbon Nanotubes Nanohybrid Films Fabricated by One-Step Co-Electrodeposition in Ionic Liquids," Electrochimca Acta, Vol. 65, 2012, pp. 64-69.

http://dx.doi.org/10.1016/j.electacta.2012.01.007

[7] Y. Mu, D. Jia, Y. He, Y. Miao and H. L. Wu, “Nano Nickel Oxide Modified Non-Enzymatic Glucose Sensors with Enhanced Sensitivity through an Electrochemical Process Strategy at High Potential,” Biosensor Bioelectronics, Vol. 26, No. 6, 2011, pp. 2948-2952. http://dx.doi.org/10.1016/j.bios.2010.11.042

[8] C. Guo, Y. Wang, Y. Zhao and C. Xu, "Non-Enzymatic Glucose Sensor Based on Three Dimensional Nickel Oxide for Enhanced Sensitivity,” Analytical Methods, Vol. 5, No. 7, 2013, pp. 1644-1647. http://dx.doi.org/10.1039/c3ay00067b

[9] J. Chen, W. D. Zhang and J. S. Ye, "Nonenzymatic Electrochemical Glucose Sensor Based on $\mathrm{MnO}_{2} / \mathrm{MWNTs}$ Nanocomposite,” Electrochemistry Communications, Vol. 10, No. 9, 2008, pp. 1268-1271. http://dx.doi.org/10.1016/j.elecom.2008.06.022

[10] X. Wang, X. Dong, Y. Wen, C. Li, Q. Xiong and P. Chen, “A Graphene-Cobalt Oxide Based Needle Electrode for
Non-Enzymatic Glucose Detection in Micro-Droplets,” Chemical Communication, Vol. 48, No. 52, 2012, pp. 6490-6492. http://dx.doi.org/10.1039/c2cc32674d

[11] M. F. Wang, Q. A. Huang, X. Z. Li and Y. Wei, "Mesoporous $\mathrm{CuO}$ : Alternative Enzyme-Free Glucose Sensing Structure with Excellent Kinetics of Electrode Process,” Analytical Methods, Vol. 4, No. 10, 2012, pp. 31743179. http://dx.doi.org/10.1039/c2ay25501d

[12] D. Tao and F. Wei, "New Procedure towards Size-Homogeneous and Well-Dispersed Nickel Oxide Nanoparticles of $30 \mathrm{~nm}$,” Materials Letters, Vol. 58, No. 25, 2004, pp. 3226-3228. http://dx.doi.org/10.1016/j.matlet.2004.06.015

[13] K. C. Liu and M. A. Anderson, "Porous Nickel Oxide/ Nickel Films for Electrochemical Capacitors," Journal of The Electrochemical Society, Vol. 143, No. 1, 1996, pp. 124-131. http://dx.doi.org/10.1149/1.1836396

[14] Y. D. Wang, C. L. Ma, X. D. Sun and H. D. Li, "Preparation of Nanocrystalline Metal Oxide Powders with the Surfactant-Mediated Method,” Inorganic Chemistry Communications, Vol. 5, No. 10, 2002, pp. 751-755. http://dx.doi.org/10.1016/S1387-7003(02)00546-4

[15] L. Xiang, X. Y. Deng and Y. Jin, "Experimental Study on Synthesis of NiO Nano-Particles," Scripta Materialia, Vol. 47, No. 4, 2002, pp. 219-224. http://dx.doi.org/10.1016/S1359-6462(02)00108-2

[16] S. Deki, H. Yanagimito and S. Hiraoka, " $\mathrm{NH}_{2}$-Terminated Poly (ethylene oxide) Containing Nanosized NiO Particles: synthesis, characterization, and Structural Considerations," Chemistry of Materials, Vol. 15, No. 26, 2003, pp. 4916-4922. http://dx.doi.org/10.1021/cm021754a

[17] B. Cheng, Y. Le, W. Q. Cai and J. G. Yu, "Synthesis of Hierarchical $\mathrm{Ni}(\mathrm{OH})_{2}$ and $\mathrm{NiO}$ Nanosheets and Their Adsorption Kinetics and Isotherms to Congo Red in Water," Journal of Hazardous Materials, Vol. 185, No. 2-6, 2010, pp. 889-897. http://dx.doi.org/10.1016/j.jhazmat.2010.09.104

[18] M. Villagran, J. Costamagna and J. H. Zagal, “Nickel(II) Complexes with Tetraaza Macrocycles in the Electrocatalytic Oxidation of Sulfite," Journal of Coordination Chemistry, Vol. 59, No. 13, 2006, pp. 1467-1476. http://dx.doi.org/10.1080/00958970600559484

[19] Z. H. Ibupoto, S. M. Usman Ali, C. O. Chey, K. Khun, O. Nur and M. Willander, "Selective Zinc Ion Detection by Functionalised ZnO Nanorods with Ionophore,” Journal of Applied Physics, Vol. 110, No. 10, 2011, Article ID: 104702. http://link.aip.org/link/doi/10.1063/1.3662107 